\title{
Sensibilização de alunos do ensino fundamental a partir de práticas ambientais no Parque Metropolitano de Pituaçu.
}

Sensitization of students of fundamental teaching from environmental practices in the Metropolitan Park of Pituaçu.

Marcelo Cesar Lima Peres', Katia Regina Benati", Priscila Maria dos Santos Silva"', Virgínia Eudes Peneluca Amorimv, Marcelo Alves Dias ${ }^{\vee}$

\begin{abstract}
RESUMO
Objetivou-se estimular o comportamento conservacionista em alunos do ensino fundamental partir de práticas ambientais no Parque Metropolitano de Pituaçu. O Parque é uma Unidade de Conservação urbana de mata atlântica, atualmente com 378 ha. Avaliamos II 6 alunos de quatro escolas adjacentes ao Parque. Executamos três fases: I. Conceitual (palestra), 2. Procedimental (observação de fauna e variáveis ambientais no Parque) e 3. Atitudinal (produção de desenhos e textos). Na primeira fase aplicamos questionários nos I I6 alunos; na segunda e terceira fase, participaram 58 alunos que responderam mais uma vez o questionário. Comparamos os questionários através do teste t e Mann-Whitney. Não houve diferença significativa, tanto em relação a média geral $\left(p=0,5970 ; t^{\prime}=0,5302\right)$, quando comparado as questões subjetivas individualmente. Este resultado é inusitado, pois, esperávamos que a participação na fase procedimental contribuiria para o aprendizado das crianças. Desta forma, consideramos o questionário uma ferramenta insuficiente, pois, sofreu interferência da euforia dos alunos na atividade procedimental. Corroboramos está inferência, quando percebemos um aprendizado dos alunos a partir da análise dos desenhos e textos produzidos após a fase procedimental. Propomos a aplicação de ferramentas que estimulam a criatividade, como criação de desenhos, jogos e textos lúdicos para avaliar práticas ambientais. Palavras-chave: Jogos educativos, Conservação Ambiental, Mata Atlântica, Educação Ambiental
\end{abstract}

ABSTRACT

The objective was to stimulate the conservationist behavior in elementary school students from environmental practices in the Metropolitan Park of Pituaçu. The Park is an Urban Conservation Unit of Atlantic forest, currently with 378 ha. We evaluated II 6 students from four schools adjacent to the Park. We performed three phases: I. Conceptual (lecture), 2. Procedimental (observation of fauna and environmental variables in the Park) and 3. Attitudinal (production of drawings and texts). In the first phase we applied questionnaires to the II 6 students; in the second and third phase, 58 students participated and they answered the questionnaire once more. We compared the questionnaires using the t-test and Mann-Whitney test. There was no significant difference, both in relation to the general average ( $p=0.5970 ; t$ ' $=0.5302)$, when compared to the subjective questions individually. This result is unusual because, we hoped that participation in the procedural phase would contribute to the learning of the children. In this way, we consider the questionnaire an insufficient tool, since it was interfered with by the euphoria of the students in the procedural activity. We corroborate this inference when we perceive a student's learning from the analysis of the drawings and texts produced after the procedural phase. We propose the application of tools that stimulate creativity, such as creation of drawings, games and play texts to evaluate environmental practices. Keywords: Educational Games, Environmental Conservation, Atlantic Forest, Environmental Education

\section{INTRODUÇÃO}

O homem vive profundas dicotomias. Dificilmente se considera um elemento da natureza, mas como um ser à parte, observador e/ou explorador da mesma. Esse distanciamento fundamenta as suas açóes tidas como racionais, mas cujas consequências graves exigem dos homens, nesse final de século, respostas filosóficas e práticas para acabar com o antropocentrismo e o etnocentrismo (REIGOTA, 2004). Diante desse quadro,

'Doutor em Ecologia, Universidade Católica do Salvador, Salvador, BA, Brasil - marcelo.peres@pro.ucsal.br

"Professora de graduação e pós-graduação da Universidade Católica do Savador, Salvador, BA, Brasil - katia.benati@pro.ucsal.br

"'Mestre em Ecologia aplicada à Gestão Ambiental, Universidade Católica do Salavador, Salavador, BA, Brasil - biocila@gmail.com

IvGraduada em Ciências Biológicas, Universidade Católica do Salavador, Salavador, BA, Brasil - virginiaeudes@yahoo.com.br

vMestre em Ciências Biológicas, Universidade Católica do Salavador, Salavador, BA, Brasil - marcelo.dias@pro.ucsal.br 
a Educação Ambiental é vista como uma maneira eficiente de conduzir mudanças efetivas de consciência e comportamento da sociedade, auxiliando no combate à crise ambiental (GUIMARÃES, 2005). A Educação Ambiental coloca a necessidade de amplificar o diálogo entre o homem e a natureza, conhecimentos científicos e conhecimentos não científicos (LEFF, 2001; ANDREOLI; ANACLETO, 2006).

A Educação Ambiental está presente no currículo escolar do Ensino Fundamental, mas é visível que a conscientização ainda não está firmada. Oliveira e Vargas (2009) mencionam que não podemos pensar a educação apenas em função de mera transmissão de conhecimentos, desconexos com a realidade percebida e vivida. Precisamos de uma nova prática educacional, transformada em práxis pela reflexão do processo educativo e das próprias concepçóes que regem esse processo. Assim, é preciso considerar o desenvolvimento de propostas de educação ambiental que, através da estimulaçáo sensorial, permitam as pessoas expressar suas emoçóes com relação ao ambiente.

Vale salientar que com a utilização de diversos meios e métodos educativos para transmitir o conhecimento sobre o ambiente natural, a Educação Ambiental enfatiza de modo adequado atividades práticas e sociais sendo uma importante ferramenta para subsidiar o debate ecológico e expandir o número de pessoas envolvidas na prática da conservaçấo e da sensibilização ambiental fundamental para formaçáo de cidadãos plenos (JACOBI, FLEURY, ROCHA, 2004).

Nesse sentido, a Educação Ambiental exercida em unidades de conservação propicia a inter-relação dos processos de aprendizagem, questionamento e sensibilização. Tendo em vista que essas áreas protegidas podem atuar não somente na preservação dos recursos naturais, mas, também como locais de aprendizagem e sensibilizaçáo da comunidade acerca da problemática ambiental esses ambientes se tornam importantes instrumentos para o desenvolvimento de práticas ambientais educativas.

Considerando que a conservaçáo desses espaços ambientais interativos depende de estratégias adotadas nos programas de Educação Ambiental, torna-se então de grande importância que eles sejam planejados e implementados adequadamente, utilizando as escolas para auxiliá-los (TOLEDO \& PELECINI, 2005). Dessa forma, vislumbrando ser imprescindível o fornecimento do embasamento teórico-prático a comunidade escolar para subsidiar o desenvolvimento de práticas de Educação Ambiental em Unidades de Conservação urbanas como Parque Metropolitano de Pituaçu.

O Parque Metropolitano de Pituaçu ( $12^{\circ} 56^{\prime} 53^{\prime \prime}$ e e $38^{\circ} 24^{\prime} 47^{\prime \prime}$ O), espaço territorial especialmente protegido criado na década de 1970 pelo Governo do Estado da Bahia, localizado na zona urbana do Município de Salvador. Um fragmento de Floresta Atlântica que abriga uma rica diversidade de fauna e flora (OLIVEIRA e CARDOSO, 2013), conta com 229 espécies de vertebrados (32 de Anfíbios; 59 de Répteis; 116 de Aves e 22 de Mamíferos) (ECOA, 2013), 80 espécies de aranhas (OLIVEIRA-ALVES et al. 2005), 70 espécies de borboletas (VASCONCELOS et al., 2009), totalizando 379 espécies animais e 258 espécies de plantas, somando 637 espécies catalogadas. Destas, quatro estáo listadas na Lista Oficial de Espécies Ameaçadas do IBAMA. Sete espécies de serpentes, duas de marsupiais, uma de canídeo e uma de morcego são listadas pelo Ministério da Saúde como sendo de interesse médico e epidemiológico. O parque possui uma lagoa artificial com $4 \mathrm{Km}$ de extensão, circundada por uma ciclovia de $15 \mathrm{~km}$ de extensão, que surgiu com a construção da represa de Pituaçu pelo engenheiro Teodoro Sampaio em 1906 para abastecimento de água de Salvador (ALMEIDA et al., 1992)

Percebe-se então, que o Parque Metropolitano de Pituaçu possui aspectos que reforçam seu potencial como um valioso instrumento de estudo e aplicação de procedimentos ambientais, sendo, portanto, imprescindível a prática de ações educativas com a comunidade escolar adjacente ao Parque, visando à sua conservação.

Neste contexto, objetivou-se promover práticas ambientais de observação de fauna (aracnídeos) e variáveis ambientais no Parque Metropolitano de Pituaçu (PMP), visando estimular o comportamento conservacionista em alunos do ensino fundamental ( $5^{\circ}$ e $6^{\circ}$ ano) da rede de ensino público.

\section{2 ÁREA DE ESTUDO}

Os fragmentos florestais urbanos de Salvador são considerados áreas de alto interesse para conservação da Mata Atlântica, pois além de estarem reduzidos a poucos remanescentes, o conhecimento a respeito destes é bastante escasso. Dentre os remanescentes existentes, oito são considerados Unidades de Conservação (U.C.), sendo o Parque Metropolitano de Pituaçu o mais representativo, pois além de possuir a maior área de mata conservada, cerca de 378 ha, possui uma área de lazer muito utilizada pela populaçáo. A utilizaçáo 
desta U.C. é feita por diversos grupos sociais, tais como, moradores do entorno, escolas de ensino médio e fundamental, universitários, pesquisadores, turistas, pescadores e comunidade local.

O PMP está classificado como Floresta Ombrófila Densa, com resquícios vegetais de Restinga, que formam um ecótono (TELES \& BAUTISTA, 2001). TELES \& BAUTISTA (2006) registraram 29 espécies de Asteraceae, sendo cinco exclusivas do Brasil. O parque presenta uma flora típica de sub-bosque, caracterizada principalmente pela presença de espécies de Melastomataceae e Arecaceae. As espécies arbóreas mais representativas pertencem às famílias Anacardiaceae, Dilleniaceae, Fabaceae e Malpighiaceae, sendo, em sua maioria, pioneiras (DIAS et al. 2007). Embora o Parque tenha um histórico de intensas perturbaçóes antrópicas, estando ainda, isolado de outros fragmentos florestais (Benati et al., 2005), o remanescente encontra-se, em estádio inicial de regeneração (DIAS et al. 2007).

Pelo fato de tratar-se de uma U.C., é imprescindível e urgente que seja desenvolvido um Plano de Manejo para o parque. Fundamentado neste contexto, o Centro de Ecologia e Conservação Animal (ECOA), grupo de pesquisa da Universidade Católica do Salvador - UCSAL cadastrado no Conselho Nacional de Desenvolvimento Científico e Tecnológico $(\mathrm{CNPq})$, vem desenvolvendo pesquisas no Parque Metropolitano de Pituaçu desde 2001, porém, suas publicações são utilizadas principalmente pela comunidade científica, não sendo direcionadas diretamente para a população local ou visitante, necessitando de um veículo que traduza estas informaçôes para uma linguagem local, já que não existem muitas informaçôes científicas sobre o Parque em linguagem acessível ao público geral (PERES et al, 2006). Sendo assim, vislumbramos que crianças, adequadamente orientadas através de práticas ambientais, fundamentadas nos princípios da Educaçáo Ambiental, podem fomentar um comportamento conservacionista, e consequentemente, podem ser os melhores agentes para a tradução destas informaçốes.

\section{METODOLOGIA}

Foram realizadas duas visitas semanais em todas as escolas e na semana seguinte a escola veio ao Centro ECOA. A principio pretendíamos trabalhar com crianças do ensino infantil.

De acordo com Firmino e Vasconcelos, (2017):

"educação ambiental quando inserida no contexto escolar, principalmente na educação infantil, tem um papel importante na preservação e conservação do meio ambiente, pois, se desde os primeiros anos de vida, a criança aprender a ter uma consciência ambiental, futuramente estas poderão se tornar agentes participativos do processo de ensino aprendizagem, em prol do meio ambiente."

Entretanto, tivemos dificuldades logísticas de trabalhar em escolas do ensino infantil adjacentes ao Parque, desta forma, optamos por alunos do $5^{\circ}$ e $6^{\circ}$ ano do ensino fundamental. Assim, foram avaliados 116 alunos do $5^{\circ}$ e $6^{\circ}$ ano do ensino fundamental de quatros escolas da rede pública adjacente ao PMP.

A avaliação seguiu três fases: (1) Conceitual: palestra ministrada por biólogos e estagiários do Centro ECOA abordando conceitos de conservaçáo ambiental (Figura 1); (2) Procedimental: observaçáo de fauna e mensuração de variáveis ambientais no PMP de acordo com as estratégias do projeto desenvolvido por MCLP (Figura 2) e (3) Atitudinal: produção de desenhos e textos relacionados ao tema de conservação, visando revelar o aprendizado das crianças.

Para as duas visitas semanais a escola, foram agendados dias de acordo com a disponibilidade de cada escola (Tabela 1). As turmas ou alunos que participaram da proposta foram definidos também pela escola, de acordo com o perfil definido previamente a partir dos objetivos do projeto. Após a aprovação da proposta pela escola, a mesma disponibilizou uma sala de aula, para a apresentação da proposta aos alunos. Esta apresentação durou cerca de 60 minutos, onde foram abordados os objetivos, conceitos de conservação e preservação, uma introdução sobre o histórico do parque e uma base conceitual sobre os animais bioindicadores utilizados no projeto. Ao final da palestra foi aplicado o questionário. $\mathrm{O}$ instrumento de pesquisa foi um questionário contendo 7 (sete) questóes subjetivas que abordavam questóes relacionadas a aspectos ecológicos do Parque (flora, fauna e fatores abióticos) e ações relacionadas a conservação ambiental. 
Figura 1: Fase conceitual - Palestra ministrada por biólogos do Centro de Ecologia e Conservação Animal (ECOA) abordando conceitos de ecologia e conservação ambiental.

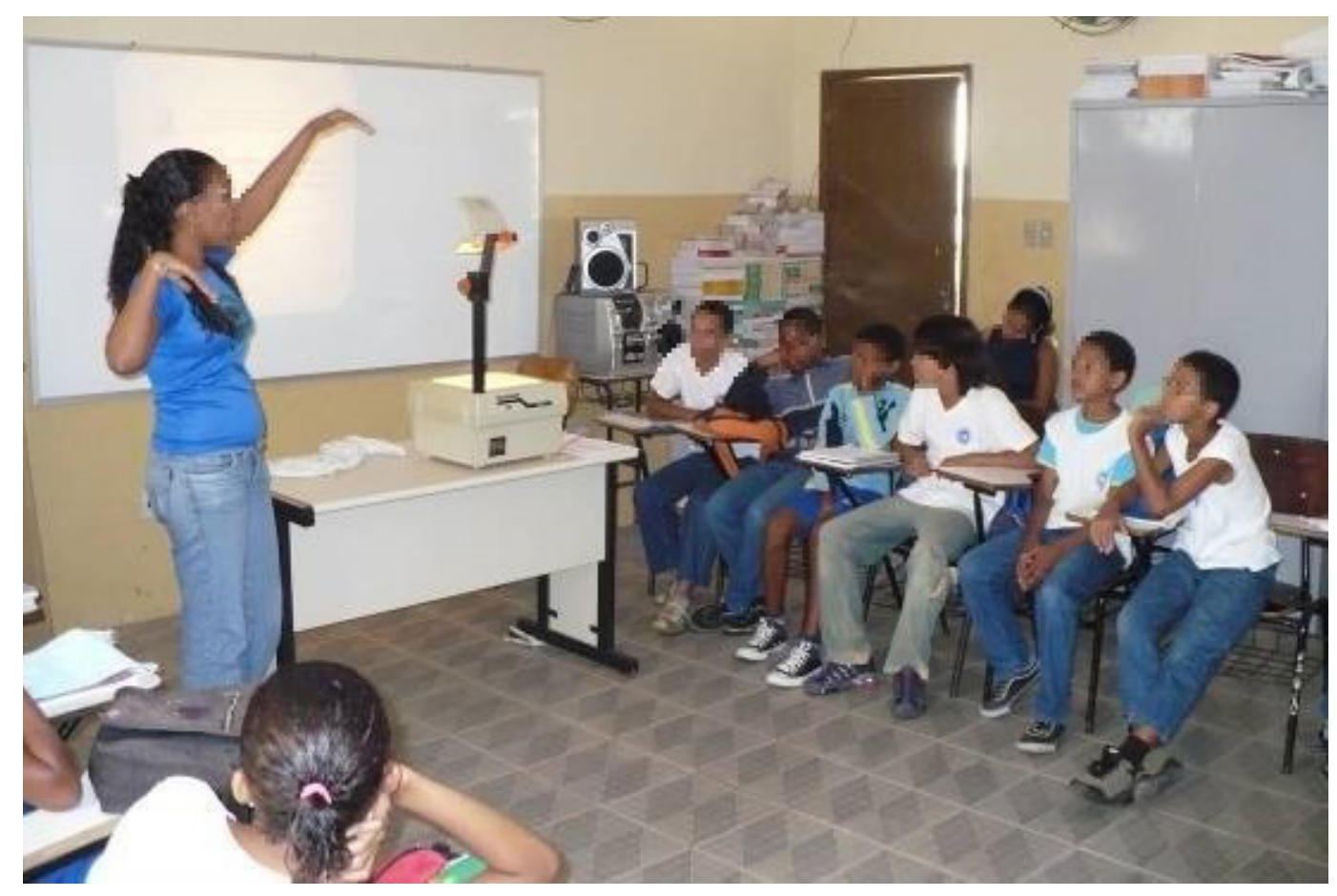

Figura 2: Fase procedimental - observação de fauna e mensuração de variáveis ambientais no Parque Metropolitano de Pituaçu de acordo com as estratégias do projeto desenvolvido por MCLP.

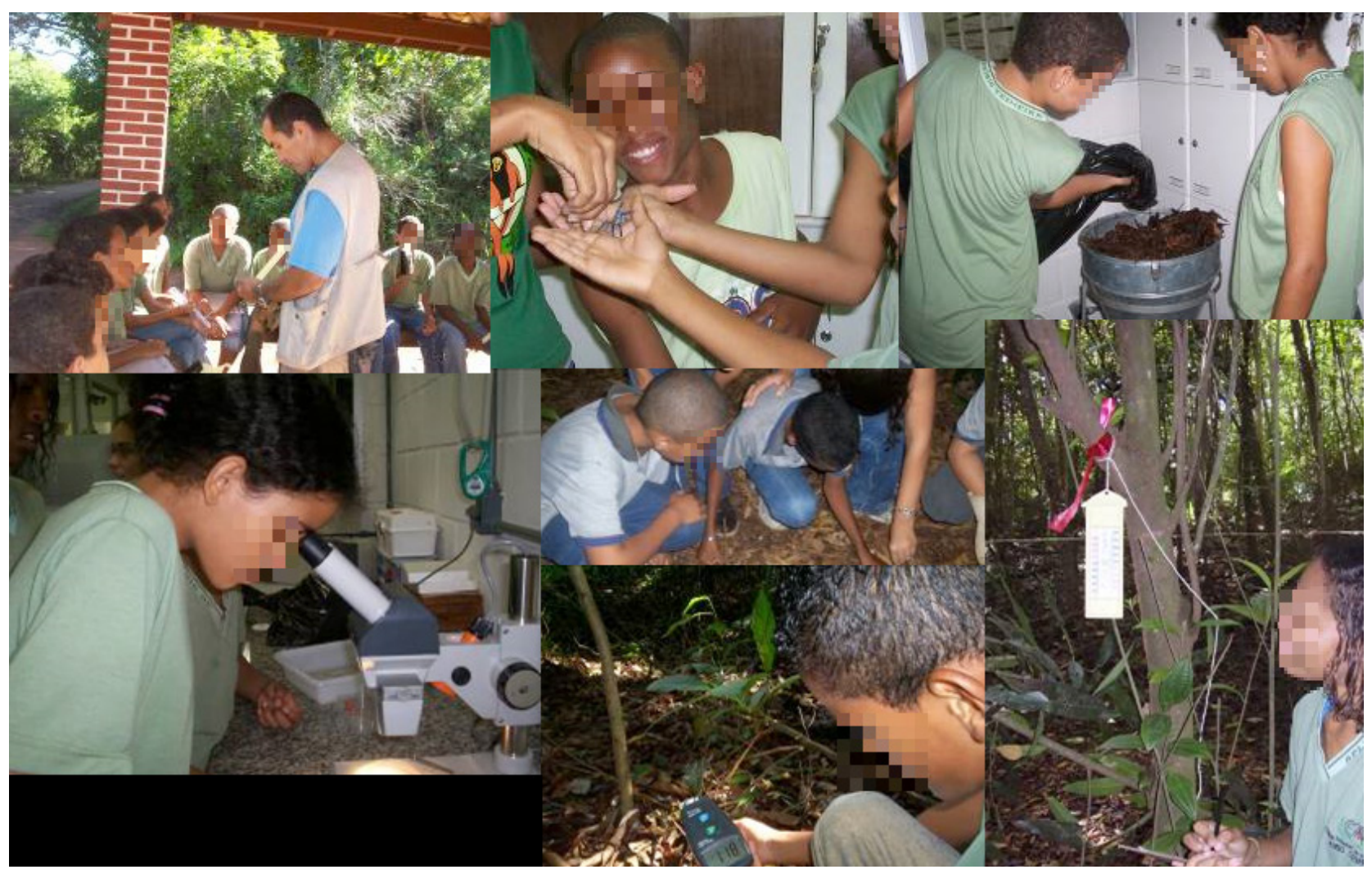


Tabela 1: Cronograma de visitas as Escolas e ao Centro de Ecologia e Conservação Animal (ECOA). As visitas a escola, denominadas de "Visita semanal 1 e 2 " foram agendadas com a escola e fizerem parte da fase "Conceitual" do projeto. A visita da escola ao Centro ECOA contemplou as fases "Procedimentais" e "Atitudinais".

\begin{tabular}{ccccc}
\hline & Escola 1 & Escola 2 & Escola 3 & Escola 4 \\
\hline Visita semanal 1 & 1a semana de março & 1a semana de abril & 1a semana de maio & 3a semana de maio \\
Visita semanal 2 & 2a semana de março & 2a semana de abril & 2a semana de maio & 4a semana de maio \\
Visita ao ECOA & 3a semana de março & 3a semana de abril & 3a semana de maio & 1a semana de junho \\
\hline
\end{tabular}

As visitas ao ECOA foram realizadas de forma a otimizar o tempo e o aprendizado. Inicialmente foi realizada uma apresentação de 30 minutos visando orientar os alunos sobre: (a) condutas e protocolos de segurança em uma área de mata, (b) técnicas de amostragem de fauna e (c) mensuraçôes de variáveis ambientais. Logo em seguida, os alunos foram divididos em três grupos, de cinco alunos e encaminhados ao PMP sob a supervisão dos professores, biólogos estagiários. Neste segundo momento, que teve uma duração de aproximadamente $2 \mathrm{~h}$, cada um dos grupos foi acompanhado por um estagiário habilitado, que conduziu o grupo a um ponto de amostra (P.A.) onde as crianças, sob orientaçáo deste estagiário, efetuaram experimentalmente as observaçóes de fauna (aracnídeos) e variáveis ambientais. Todo o processo foi coordenado por um biólogo do Centro ECOA. Os métodos de amostragem realizados pelos alunos foram replicas dos métodos aplicados no plano de monitoramento desenvolvido neste projeto.

Ao final, os grupos foram novamente reunidos no ECOA, onde solicitamos que os alunos produzissem materiais (texto e desenhos) sobre conservação, especialmente sobre o PMP. Este material foi triado e analisado e utilizado para a produção de cartilhas que foram disponibilizadas as comunidades do Parque.

Para avaliar a eficiência dos procedimentos foram aplicados questionários abordando aspectos ecológicos do Parque (flora, fauna e fatores abióticos) e açóes relacionadas a conservação ambiental. Os questionários foram aplicados para todos os alunos que participaram apenas da fase conceitual. Este mesmo questionário foi aplicado para os alunos que participaram da fase procedimental.

Para comparar o rendimento dos questionários entre os alunos que participaram apenas da fase conceitual e os que participaram das fases conceitual e procedimental, foi utilizado o software Instat $\odot$, através do qual aplicamos os testes $t$ para comparar as médias gerais e Mann-Whitney para comparar as questóes subjetivas individualmente, pois os últimos dados náo passaram nos testes de normalidade, verificados por Kolmogorov-Smirnov. O nível de significância adotado foi de 0,05 . O gráfico referente ao desempenho (=notas) dos alunos foi gerado através do Microsoft Excel 2010.

\section{RESULTADOS E DISCUSSÃO}

A nota média dos alunos que participaram apenas da fase conceitual (Grupo 1) foi 8,43, discretamente mais elevada as notas dos alunos que participaram também da fase procedimental (Grupo 2), que atingiram a média de 8,17 (Gráfico 1). No entanto, não houve diferença significativa entre o grupo de alunos que participaram apenas da fase conceitual e os alunos que participaram das fases conceitual e procedimental, tanto em relação à média geral $(p=0,5970 ; \mathrm{t}=0,5302)$, quando comparado as questôes subjetivas individualmente, questão $5(p=0,5071 ; U=1802,0)$, questão $6 \quad(p=0,5196 ; U=1798,5)$, questão $7(p=0,9358 ; U=1697,0)$. Este resultado é inusitado, pois, esperávamos que a participação na fase procedimental pudesse contribuir para o aprendizado das crianças.

Sendo assim, corroboramos com o proposto por Guimarães (2005), que acredita que a avaliação através de questionários pode náo ser o mais adequado para projetos de educaçáo ambiental. Desta forma, sugerimos que o questionário é uma ferramenta necessária para reduzir a subjetividade, mas, insuficiente para a avaliação de práticas ambientais com crianças na faixa etária avaliada, pois, a aplicação do mesmo sofre influência da euforia dos alunos na atividade procedimental. Além disso, Guimarães (2005) acredita que avaliações quantitativas, correm o risco de prescindir de elementos que melhor caracterizam um projeto de educação ambiental. 
Gráfico 1 - Valores médios das notas obtidas a partir dos questionários aplicados em quatro escolas da rede pública de ensino adjacente ao Parque Metropilitano de Pituaçu, para alunos do $5^{\circ}$ e $6^{\circ}$ ano do ensino fundamental. Grupo 1 (fase conceitual) e grupo 2 (fase conceitual e procedimental). Aplicamos os testes t para comparar as médias gerais e MannWhitney para comparar as questóes subjetivas individualmente. Não encontramos diferenças significativas. O nível de significância adotado foi de 0,05

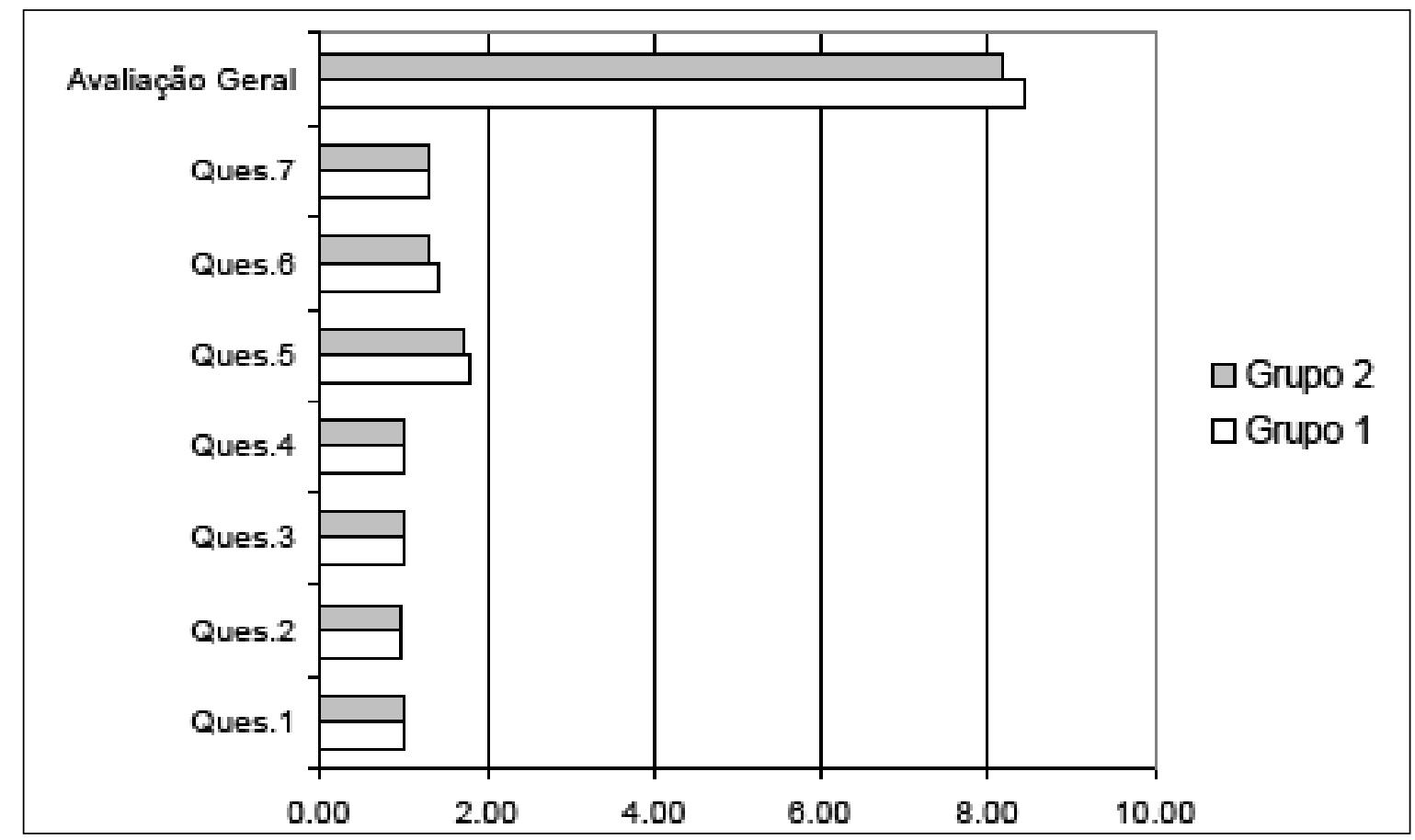

Ao avaliarmos os desenhos produzidos pelas crianças dos dois grupos (fase conceitual e fase procedimental), com a assessoria de uma psicopedagoga percebemos indícios de um aprendizado dos alunos após a atividade procedimental (Figura 3a e 3b). Portanto, considerando-se que de acordo com Morales (2004), os desenhos, pintura e poesia, proporcionam aos participantes a representação simbólica dos seus conceitos, instigando sua imaginação, criatividade e liberdade de expressão e a dramatização e que Goldberg (2005) acredita que a partir do desenho a criança organiza informaçóes, processa experiências vividas e pensadas, revela seu aprendizado e pode desenvolver um estilo de representação singular do mundo.

Figura 3: Produção de desenhos dos alunos relacionados ao tema de flora e fauna do Parque Metropolitano de Pituaçu.

(A) Desenho criado pelos alunos na fase conceitual. (B) Desenho criado pelos alunos na fase procedimental.
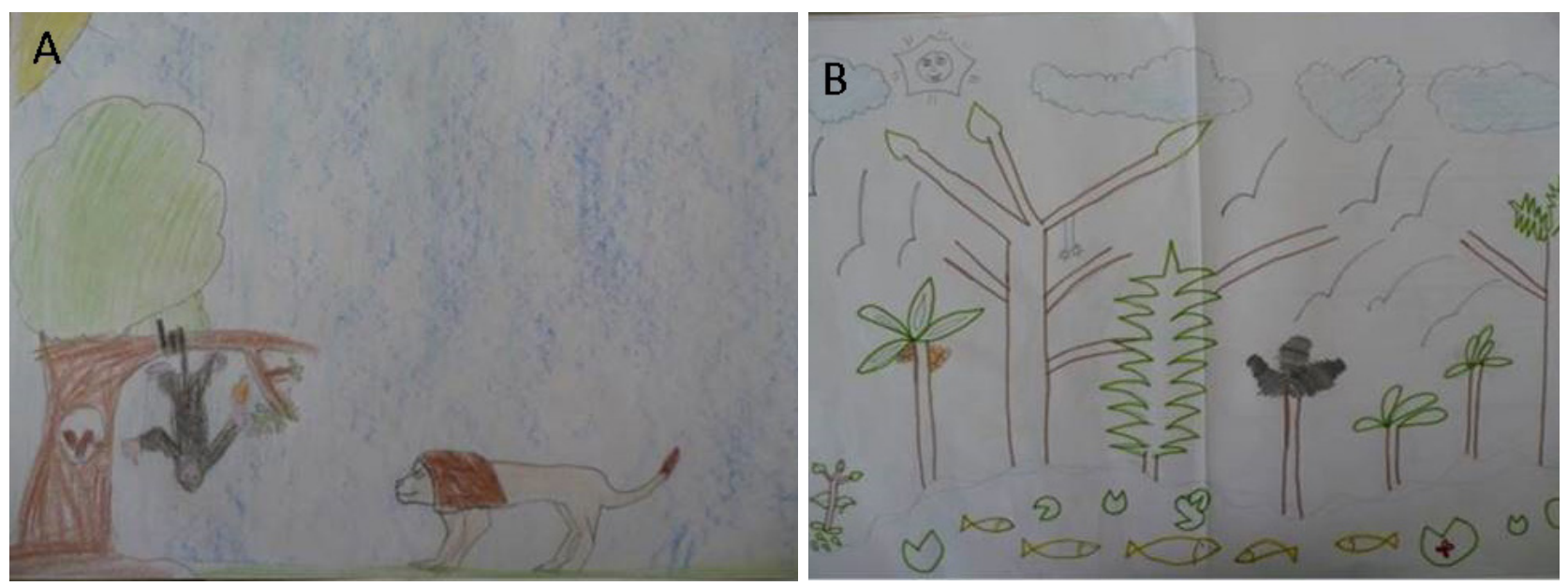


\section{CONCLUSÕES}

Desta forma, considerando os participantes da pesquisa, crianças do $5^{\circ}$ e $6^{\circ}$ ano do ensino fundamental. Propomos que ferramentas que estimulam a criatividade, como criaçáo de desenhos, jogos e textos, sejam aplicadas na fase conceitual permitindo comparaçōes (inclusive estatística) entre as fases conceitual e procedimental. Também recomendamos que as atividades conceituais e procedimentais, assim com a avaliaçáo destas, se estendam pelo menos por um ano letivo. Além disso, consideramos essencial a participação mais efetiva dos professores da turma contribuindo para uma interação mais consistente entre a equipe do projeto e o corpo docente e discente da escola.

\section{AGRADECIMENTO}

Gostaríamos de agradecer a Thiago Bols e Neia Estevam pelas análises dos desenhos. Priscila Maria dos Santos Silva foi Bolsista de Iniciação Científica da Fundação de Amparo à Pesquisa do Estado da Bahia.

\section{REFERÊNCIAS}

ANDREOLI, V.M. \& ANACLETO, A. 2006. Compartilhando saberes: os conhecimentos tradicionais e a educação ambiental. In: Encontro Paranaense de Educação Ambiental- EPEA, IX, 2006, Guarapuava, s/p.

BENATI, K.R. SOUZA-ALVES, J.P.; SILVA, E.A.; PERES, M.C.L. \& COUTINHO, E.O. 2005. Aspectos comparativos das comunidades de aranhas (Araneae) em dois remanescentes de Mata Atlântica da Bahia, Brasil. Biota Neotropica. vol.5, n.1A.

DIAS, F.G.K.; SILVA, V.I.S.; AGUIAR, L.G.P.A. \& MENEZES, C.M. 2007. Levantamento preliminar da flora vascular do Parque Metropolitano de Pituaçu, Salvador - Bahia. In: Anais da X Semana de Mobilização Científica- SEMOC, Salvador, p. 33- 43

ECOA. 2009. Animais e Plantas do Parque Metropolitano de Pituaçu - Lista de Espécies. Disponível em:https://www. researchgate.net/publication/280000495_Lista_de_Especies_da_Fauna_e_Flora_do_Parque_de_Pituacu_Salvador_ Bahia_Brasil. Acesso: 18/09/2018.

GOLDBERG, L.G. 2005. Psicologia em estudo, Maringá, vol. 10. nº. 1, pág. 97-106.

GUIMARÃES, A.Q. et al. 2005. Projeto Pampulha limpa: fazendo educação ambiental em uma grande cidade. Anais do $8^{\circ}$ encontro de extensão da UFMG. Belo Horizonte.

JACOBI, C.M.; FLEURY, L.C. \& ROCHA, A.C.C.L., 2004. Percepção Ambiental em Unidades de Conservação: experiência com diferentes grupos etários no Parque Estadual da Serra do Rola Moça, Minas Gerais. Anais do 7o Encontro de Extensão Universidade Federal de Minas Gerais. Belo Horizonte: 12 a 15 de set.

LEFF, E. Complexidade, interdisciplinaridade e saber ambiental. In: PHILIPPI, Jr. (Ed) Interdisciplinaridade em Ciências Ambientais, São Paulo, Editora Signus, 2000, p. 20-48.

MORALES, A.G. 2004. A arte do afeto na educação ambiental. In: Convenção Latino América, Congresso Brasileiro e Encontro Paranaense de Psicoterapeutas Corporais, Foz do Iguaçu.

OLIVEIRA, T. P. \& CARDOSO, F.M. 2013. Dimensóes Jurídico-Institucionais da questão social em áreas protegidas: O caso do Parque Metropolitano de Pituaçu, Salvador (Bahia). Revista Capital Científico - Eletrônica (RCCe) v. 11, p. 1.

OLIVEIRA-ALVES, A.; PERES, M.C.L.; DIAS, M.A.; CAZAIS-FERREIRA, G.S. \& SOUTO, L.R.A. 2005. Estudo das comunidades de aranhas (Arachnida: Araneae) em ambiente de Mata Atlântica no Parque Metropolitano de Pituaçu PMP, Salvador, Bahia. Revista Biota Neotropica v.5, n.1a, p.91-98. 
OLIVEIRA, T.L.F. \& VARGAS, I.A. 2009. Vivências integradas à natureza: Por uma Educação Ambiental que estimule os sentidos. Revista Eletrônica do Mestrado de Educação. Ambiental, v. 22.

PERES, M.C.L., BENATI, K.R., LOPO, E.LC. LNS, M.F., PEREIRA, F., MÁXIMO, C.O. \& MÁXIMO P.O. 2006. Proposta de monitoramento do Parque de Pituaçu e sensibilização de alunos do ensino fundamental. In: Anais da IX Semana de Mobilização Científica- SEMOC, Salvador, p. 1-8.

REIGOTA, M. 2001. O que é educação ambiental. Coleção primeiros passos, São Paulo: Brasiliensi, 292p.

TELES, A. M. \& BAUTISTA, H. P. 2001. Flora do Parque Metropolitano de Pituaçu e seus arredores, Salvador, Bahia: Compositae. In: Anais do 52 Congresso Nacional de Botânica. João Pessoa, PB, 235p.

TELES, A. M. \& BAUTISTA, H. P. 2006. Asteraceae no Parque Metropolitano de Pituaçu, Salvador, Bahia, Brasil. Lundiana 7(2): 87-96.

TOLEDO, R.F. \& PELECINI, M.C.F. Educação ambiental em unidades de conservação. In: Educação ambiental e a sustentabilidade. São Paulo: Manole, 2005.

VASCONCELOS, R.N., BARBOSA E.C.C. \& PERES, M.C.L. Borboletas do Parque Metropolitano de Pituaçu, Salvador, Bahia, Brasil. Revista Sitientibus série Ciências Biológicas v. 9, p.158-164, 2009. 